\title{
BACTERIA - MILK QUALITY CONCERN AND EFFECTS OF DIFFERENT PREPARATION METHODS
}

\author{
M. M. Moeini, \\ College of Agriculture, Razi University, Kermanshah,Iran. \\ M.R.Sanjabi,
}

Agriculture Institute, Iranian Research Organization for Science \& Technology (IROST).

\begin{abstract}
As a Total Bacterial Count (TBC) is a one of the biggest problems of dairy farmers whom had a contract with Dairy factories in Tehran, a study was designed to determine which main factors are responsible in TBC control strategies and time to time variation in it.

The official an average Bulk Tank Somatic Cell Count (BTSCC) of 30 herds with approximately 10000 milking cows during Mar 2000-Feb 2001 has been collected from two major privet and governmental dairy processing factories in Tehran. Due to variation in TBSCC between consecutive milk testing, cows attended when at least two of the last three tests have shown variations. These tests at monthly basis have been used as an aid in determining main factors, which are responsible for unpredicted variations

In addition, preventing faulty milking procedures and effectiveness of clipping, manual drying, predip, etc. The monthly California Mastitis Test (CMT) was used for each quarter of each cow for mastitis sign and the data of BTSCC has been used in combination with CMT. The standard procedures for sampling and culturing which has been recommended by National Mastitis Council of USA in web sites of nmconline.org are used. The SAS package's was used for data analyzing with GLM program. The effects of Herd, Season and Month on BTSCC were significant $(p \leq 0.05)$ and highest BTSCC was belong to summer (1117265 \pm 144880$)$ which followed by autumn $(749276 \pm 114684)$, winter $(384490 \pm 109601)$ and spring $(218381 \pm 192742)$ respectively. The increased BTSCC in summertime probably is generated due to warm and moist environment that increases pathogen exposure and numbers. The animal stress of high temperatures and excess humidity also may increase susceptibility to new infection and thus higher SCC.

The most contagious bacteria source was Staphylococcus (Coagulas + ) and environmental bacteria sources were mainly Coliforms and Bacillus. The drying method with one used paper caused an effective significant decrease of $35 \%$ in bacterial contamination. The results are in accordance with results of previous studies in abroad but it is a first study of this kind in Iran.
\end{abstract}

\section{References}

Bagly, C.V, 1997, Controlling Coliform mastitis, Utah State University, Logan UT 84322-5600,USA.

Visschr, A, W, 1998, Staph Aureus and bulk tank culturing, Dairy management counsultant, Calgary, 287-3078, Canada. 